\title{
Canons of Animal Aesthetics
}

\section{A Report on the Exhibition Beauté Animale, Grand Palais, Paris, France, March $21^{\text {st }}$ - July $16^{\text {th }}, 2012$}

\section{Eleonora Adorni}

Independent Scholar, Member of the SIUA (School of Human-Animal Interaction)

doi: 10.7358/rela-2013-001-ador

eleonora.adorni@gmail.com

Throughout history, artists have chosen to represent certain animal species over many others, using specific aesthetic canons for their paintings, sculptures and various handcrafts. Which animals are they? And why? How has the representation of animals changed over time? These are the main questions which Beauté Animale posed to visitors. The exhibition was divided into three sections: Observation, Prejudice and Discoveries. The animals in the first section, Observation, were deemed worthy of being represented in virtue of aesthetic standards; while the animals in the second section, Prejudice, embodied widespread loci of fear, repulsion and bias; the animals portrayed in the third and final section, Discoveries, epitomized the exotic and thus the most elaborate creations of the artists themselves.

What was the fil rouge of this exhibition? The artworks - realized during an arc of time which covers the period from the Renaissance to the present day - portrayed, almost exclusively, nonhuman animals, so revealing the main objective of the curators, which was to highlight the importance of animals in the history of art. In Beauté Animale the animals were the main, if not the only protagonists of the artworks, forcing the visitor to leave behind the idea of those other animals so very often represented as corollary to the human world.

During the Renaissance the 'real' animals took their place in the realm of art to become an important element to be observed and, in the light of the ancient logic that ties the act of viewing to the act of knowing, also constituted an important element to be understood. The origins of what we call 'art animalier' is to be found in this practice: animals were usually depicted in their natural habitat or against a background, aiming to provide a visual correspondence with the detailed descriptions that most naturalists drew of them. 
Despite the naturalistic approach representing animals in a realistic way, every cultural product (in this case, artworks) inevitably reflects and carries the signs of the historical period and the social milieu that generated it, thus working like a kaleidoscope that is able to transform the reality of the animals as well. This process was clearly evident in the second part of the exhibition, Prejudice, which was dedicated to the animals that have always inspired fear, phobias, and numerous forms of superstitions. In this section, the main protagonists were the two toads by Picasso and several bats (one of these drawn by van Gogh). Bats are mammals that are usually associated with the 'inverted' life of the nocturnal world and are also an ideal source of folk tales and beliefs related to misfortune and bad luck.

In the third section the central topic was the display of exotic animals which are now specimens, a meeting point of scientific curiosity (animals as species) and voyeuristic gaze (animals as objects). Animals which were taken away from their natural environment to be put in cages and pens, represented 'models' for the reification of 'live nature' that had the ability to impress and charm both the visitor and the artist with bodies which were very different from 'normal' canons of animal beauty that we can see in everyday life.

Artists aimed to capture the animal world in the most realistic way, but Gilles Aillaud opened up a completely different perspective by showing that animal beauty is no longer the ultimate goal and now serves as a tool to stimulate and engage serious considerations on the ethical issue that animal captivity inevitably carries with it. The so-called 'animal question' emerged in the Seventies and has since then generated a pragmatic consideration on how humans relate to and treat other living beings in various contexts. With this in mind, Gilles Aillaud chose to represent animals in zoos - confined, caged, or living in putrid pools of water - to reveal the contemporary obsession of humans with satisfying their objectifying gaze, and, in doing so, deprive animals of their freedom transforming them into empty simulacra. Aillaud queries seem to have been: "What we can truly learn about animals, if we place them outside of their natural habitats?"; "What do we know about animals if we feed them with our own hands and have made them unresponsive to the presence of visitors?".

The itinerary traced by Beauté Animale concluded with the Ours Blanc by Gilles Aillaud. The polar bear lying on the icecap reminds us of a big empty bag carelessly thrown away after use. Visitors are encouraged to reflect about the cost of this objectification to the animals themselves, dissected and reassembled, as they are. The animal becomes the product of our own projections, the cultural product that meets our long-standing stereotypes about what it means to be an animal. In this sense, animals 
behind bars at the zoo, or behind a glass at the aquarium, tell us more about the collecting nature of Homo sapiens, rather than their own 'animal nature' and, finally, embody our archetypical fear, which tends to mark the distance from our own to the nonhuman world. Art, as a particular expression of that macro-phenomenon which we call 'culture', can help us to interpret the relationship between humans and animals. Along the historical and thematic path suggested by the exposition, it was possible to observe - in all its visual immediacy - how inter-specific relationships have changed over time.

Furthermore, the Parisian exhibition revealed the often unacknowledged or, at least, underestimated role of animals in human ontopoietic processes. The animals represented in the various artworks were unquestionably the protagonists of Beauté Animale. However, it must be emphasized that they were also cultural products, the result of an artist's vision, inspiration, and artistic, therefore cultural, processes. Although human figures were absent from the picture of animals, the invisible human presence pervades the artwork illuminating the representation of these animals by human hands. 